\title{
Temperature / Soot Volume Fraction Correlations in the Fuel-Rich Region of Buoyant Turbulent Diffusion Flames
}

\author{
Y. R. SIVATHANU and G. M. FAETH \\ Department of Aerospace Engineering, The University of Michigan, Ann Arbor, MI 48109-2140
}

\begin{abstract}
Instantaneous soot volume fractions and temperatures were measured in the fuel-rich (underfire) region of turbulent nonpremixed acetylene, propylene, ethylene, and propane flames burning in still air. Large-scale, highly buoyant, pool-like flames were considered, having characteristic residence times greater than $250 \mathrm{~ms}$ and burner exit Richardson numbers greater than 18. Measurements were made using an optical probe that involved laser extinction for soot volume fractions and two-wavelength pyrometry for temperatures. Strong correlations were found between soot volume fractions and temperatures for each fuel-relatively independent of burner operating conditions and position in the underfire region. This behavior is supportive of the existence of nearly universal relationships between soot volume and mixture fractions in the underfire region of turbulent nonpremixed flames having large characteristic residence times. Underfire soot is largely confined to a narrow range of mixture fractions (yielding a soot spike) and temperatures. The latter observation supports approximations of constanttemperature soot layers that have been proposed in the past for estimates of continuum radiation from soot-containing diffusion flames.
\end{abstract}

\section{NOMENCLATURE}

$a$

$\boldsymbol{A}$

$b_{\lambda}$

$c$

$d$

$d_{p}$

$f_{v}$

$f_{\lambda}$

$h$

$i$

$I_{\lambda}$

$k$

$L$

$n$

$r$

$\operatorname{Re}$

$\mathrm{Ri}$

$T$

$(-1)^{1 / 2}$

temperature acceleration of gravity

proportionality constant

instrument sensitivity at $\lambda$

speed of light

burner exit diameter

soot particle diameter

soot volume fraction

refractive index parameter (Eq. 2)

Planck's constant

spectral radiation intensity

Boltzmann's constant

length of optical path

real part of soot refractive index

radial distance

Reynolds number

Richardson number
$T_{\mathrm{L}}, T_{\mathrm{H}}$ low- and high-temperature peaks of conditional pdf of temperature

$T_{M} \quad$ mean value of conditional pdf of temperature

$u \quad$ streamwise velocity

$V_{\lambda} \quad$ voltage output of instrument at $\lambda$

$x \quad$ height above burner

\section{Greek Symbols}

$\varepsilon_{\lambda} \quad$ spectral emissivity

$\kappa \quad$ imaginary part of soot refractive index

$\lambda$ wavelength

$\nu \quad$ kinematic viscosity

$\sigma \quad$ standard deviation of conditional pdf of temperature

\section{Subscripts}

0 burner exit condition, incident laser beam

Copyright (C) 1990 by The Combustion Institute Published by Elsevier Science Publishing Co., Inc. 655 Avenue of the Americas, New York, NY 10010 


\section{INTRODUCTION}

Continuum radiation from soot is an important aspect of hydrocarbon-fueled fires because it influences their spread rates, burning rates, and structure $[1,2]$. The geometric feature of soot that affects radiation is the soot volume fraction, rather than particle size and shape distributions, since the Rayleigh limit for small particles is generally acceptable for estimating the spectral absorption coefficients of soot and scattering can be ignored [3]. Prompted by this observation, measurements of soot volume fractions and other scalar properties relevant to radiation were recently completed in this laboratory for the fuellean (overfire) region of buoyant turbulent diffusion flames $[4,5]$. The objective of the present investigation was to extend this work to the fuelrich (underfire) region of similar flames. The study was limited to highly buoyant, pool-like, turbulent fires burning in still air; therefore, the findings are primarily relevant to natural (unwanted) fires. The test fuels included acetylene, propylene, ethylene and propane-all of which yield flames having significant levels of continuum radiation from soot [4-7].

The present study also extended earlier efforts to evaluate the laminar flamelet concept for soot volume fractions in diffusion flames [4-7]. This concept has been proposed for use in conjunction with the conserved-scalar formalism, as a means of avoiding the complexities of soot chemistry in turbulent environments when estimating the continuum radiation properties of turbulent flames $[6,7]$. The key hypothesis of the laminar flamelet concept for diffusion flames is that instantaneous scalar properties are only functions of the instantaneous mixture fraction (called state relationships). The concept was initially proposed by Bilger [8]; furthermore, a number of subsequent studies have found satisfactory state relationships for major gas species, even for flames with large concentrations of soot, except near points of flame attachment or extinction [4-1].

The existence of state relationships for major gas species prompted earlier studies in this laboratory to see whether soot volume fractions behaved in the same manner [4-7]. The status of this work can be conveniently summarized by the plots of soot volume fractions as a function of mixture fraction for acetylene and ethylene-air diffusion flames illustrated in Fig. 1. Measurements shown in Fig. 1 were obtained for a variety of burners, flame operating conditions, and positions within the flames-see Refs. 4-7 for details. These factors are not designated on the plots to avoid cluttering; however, to the extent that the laminar flamelet concept for soot volume fractions is correct, soot volume fraction should be only a function of mixture fraction.

Past studies of soot volume fraction state relationships for fuel-rich conditions have been limited to laminar acetylene and ethylene flames burning in still air $[6,7]$. The results plotted in Fig. 1 show that soot volume fractions are appreciable only for relatively narrow ranges of mixture fractions (called soot spikes) for fuel-rich conditions. The state relationship correlations for the soot spikes are poorer than for major gas species [4-11]; nevertheless, estimates of the radiation properties based on these correlations were still reasonably good, suggesting that some dispersion of soot volume fraction state relationships can be tolerated for radiation predictions $[6,7]$.

Past studies of soot volume fraction state relationships for lean conditions involved the overfire region of sooting turbulent flames $[4,5]$. It was found that soot generation efficiencies (the percentage of fuel carbon that is converted to soot and emitted from the flame) were constant throughout the overfire region for a given fuel and burner operating condition. Furthermore, soot generation efficiencies increased with flame residence time at first but then became constant for times longer than roughly ten times the residence time at the laminar smoke point [5]. Because soot densities in the overfire region are relatively independent of fuel type and operating conditions [12], whereas carbon from the fuel is a passive scalar proportional to mixture fraction, this implies a universal state relationship for soot volume fractions in the overfire region at long residence times. The results illustrated in Fig. 1 for fuel-lean conditions were obtained within the long residence time regime: the measurements for various operating conditions and positions in the 


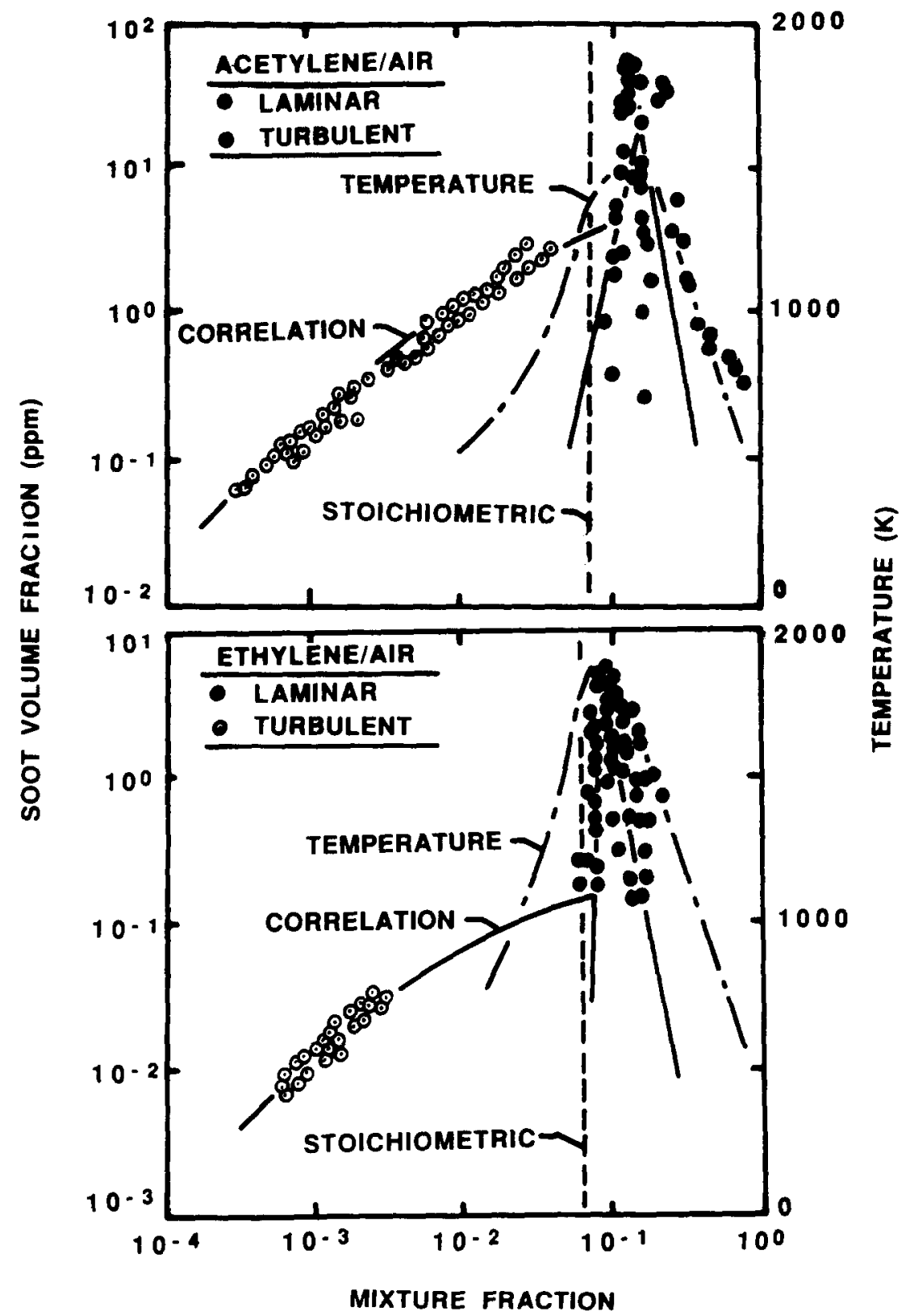

Fig. 1. Soot volume fraction state relationships for acetylene/air and ethylene/air diffusion flames. Data and correlations from Refs. 4-7.

overfire region are seen to be only a function of mixture fraction and correlate quite well with expressions based on constant soot generation efficiencies and density for acetylene and ethylene. Similar results for propylene and propane can be found in Ref. 5 .
Based on these findings, the main issues are whether the properties of the soot spike observed in laminar flames are similar within turbulent flames; and when, if at all, the soot volume fraction state relationship concept is appropriate for the fuel-rich (underfire) region of turbulent 
flames. A formal test of these properties requires simultaneous measurements of soot volume fraction and mixture fraction at a point, with sufficient temporal resolution to control effects of gradient broadening. This is difficult to achieve in turbulent flames: the soot spike involves a relatively small range of mixture fractions (see Fig. 1), imposing stringent accuracy requirements in a difficult environment, whereas existing methods for rapidly measuring mixture fractions in turbulent environments either lose sensitivity in the presence of soot or might interfere with soot chemistry. Thus, an indirect approach was used instead, simultaneously measuring soot volume fractions and temperatures with an optical probe and inferring whether these findings were consistent with the existence of the soot spikes observed for fuel-rich conditions in Fig. 1. An auxiliary benefit of this approach is that it directly provides soot volume fractions and temperatures-the two main scalar properties affecting continuum radiation from soot-containing flames. Measurements were limited to relatively large flames within the long residence time regime with respect to soot generation efficiencies in the overfire region. This helped to minimize problems of spatial resolution while providing a test of whether long residence time behavior in the overfire region would extend to the fuel-rich (underfire) region as well. The measurements involved both probability density functions (pdfs) of temperature, conditioned on soot volume fraction, and the correlation between temperatures and soot volume fractions.

\section{EXPERIMENTAL RESULTS}

\section{Apparatus}

The apparatus was similar to the arrangement used earlier for studies of the overfire region [5]. This involved vertically upward injection of fuel in still air with the flames attached at the burner exit. The flames burned within a large enclosure $(2.4 \times 2.4 \times 3.6 \mathrm{~m}$ high $)$ with a metal hood and adjustable exhaust system at the top to remove the combustion products. Room disturbances were reduced by using strips of plastic film as the side walls of the enclosure, as well as a smaller screened enclosure $(1 \times 1 \times 2 \mathrm{~m}$ high $)$ directly around the flames. The optical probe was mounted rigidly; therefore, the flame was traversed to provide measurements at various points within the underfire region.

A sketch of the burner appears in Fig. 2. The burner exit was $50 \mathrm{~mm}$ in diameter. The fuel entered the bottom of the burner and then passed through a honeycomb section $(3 \mathrm{~mm}$ cell size $\times$ $40 \mathrm{~mm}$ long) to remove any residual swirl. The flow subsequently passed through two more plenum sections and two beds of steel balls ( 5 and $3 \mathrm{~mm}$ in diameter with bed heights of $25 \mathrm{~mm}$ ) to provide a uniform flow at the burner exit. The burner was cooled by water flowing through a coil soldered to its outside surface. The flames attached naturally at the exit of the burner.

\section{Instrumentation}

\section{Optical Probe}

The optical probe involved laser extinction to measure soot volume fractions and two-wavelength pyrometry to measure temperatures. The probe is illustrated in Fig. 3: it consisted of two light guides, mounted opposite one another, tapered to open view ports ( $3 \mathrm{~mm}$ in diameter) at their tips. The light guides were purged with a $1-\mathrm{cm}^{3} / \mathrm{s}$ flow of nitrogen which passed out of the open viewing ports, however, increasing the nitrogen flow rate up to $3 \mathrm{~cm}^{3} / \mathrm{s}$ had little effect on the measurements.

Choosing the optical path length was a compromise between reducing effects of gradient broadening by minimizing the length, and improving signal-to-noise ratios and reducing disturbances of the flow by the probe by increasing the length. Based on these considerations, the distance between viewing ports was $10 \mathrm{~mm}$ for the acetylene flames and $20 \mathrm{~mm}$ for the other flames. The larger path length for the more weakly sooting fuels helped extend the dynamic range of the soot volume fraction measurements. Minimum integral-scale lengths were estimated to be roughly $20 \mathrm{~mm}$ for the range of the measurements so the longer path length was marginal, however, varying path lengths in the range $10-30 \mathrm{~mm}$ had little 


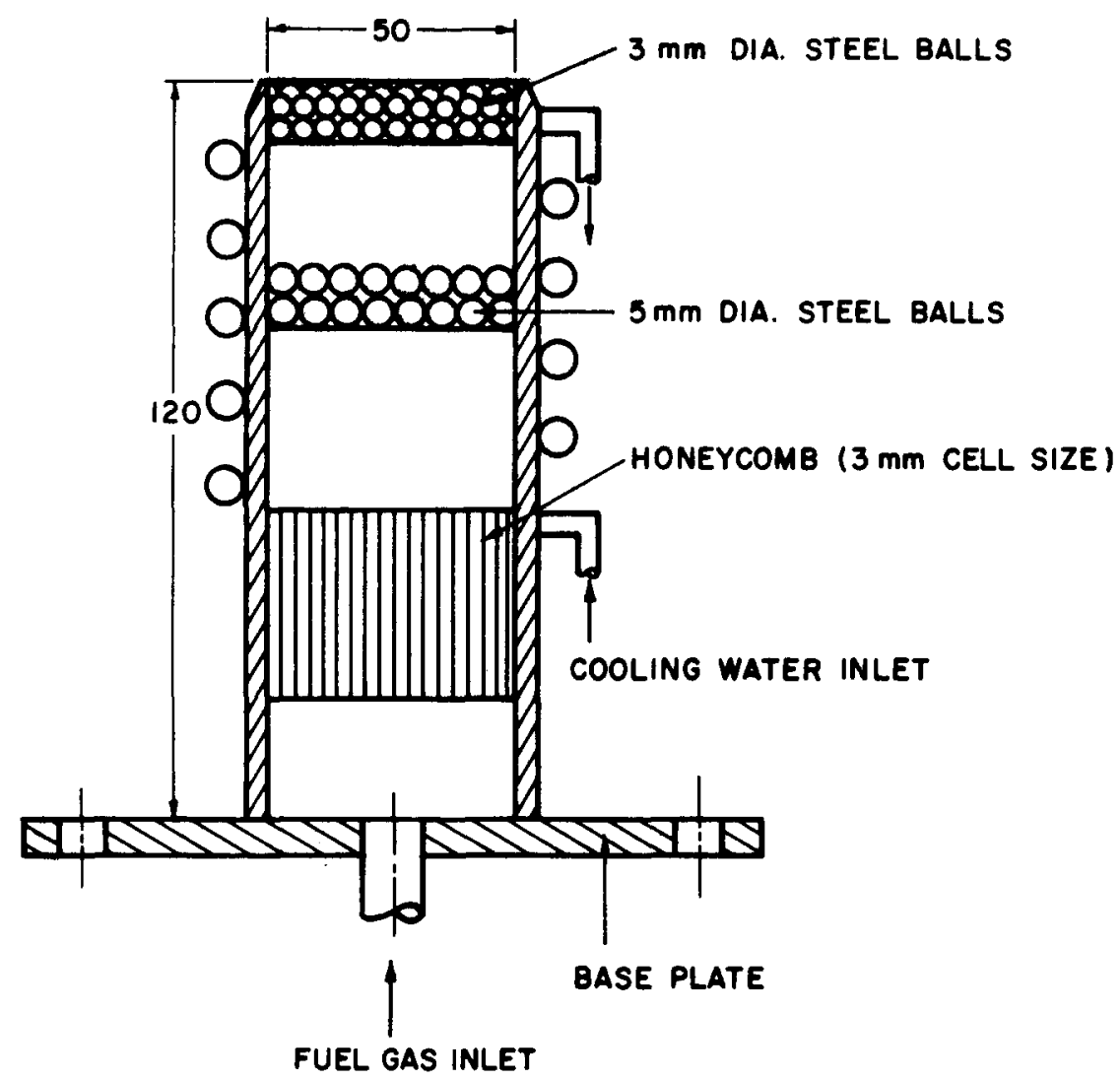

ALL DIMENSIONS IN $\mathrm{mm}$

Fig. 2. Sketch of the 50-mm-diameter burner.

effect (less than $30 \mathrm{~K}$ ) on the temperature measurements and observations of maximum soot volume fractions. It will also be seen that the general behavior of the soot volume fraction and temperature measurements was similar for acetylene and other fuels, in spite of the 2:1 increase of optical path length, suggesting that gradient broadening did not influence the major conclusions of the study excessively.

\section{Soot Volume Fractions}

Soot volume fractions were measured by laser extinction across the gap between the viewing ports, using the $632.8-\mathrm{nm}$ line of a $\mathrm{He}-\mathrm{Ne}$ laser (15 mW, Spectra Physics Model 124B, with a 1.1-mm-diameter beam at the $e^{-2}$ points). Two detectors (Newport Model 982 Laser Power Meters) were used to measure the intensity of the laser beam before and after passing through the flame, in order to compensate for variations of laser power. The detector for transmitted radiation had a large active area $\left(100 \mathrm{~mm}^{2}\right)$ and a response within $99 \%$ at $\pm 3 \mathrm{~mm}$ from the axis with an angular misalignment of $\pm 2^{\circ}$; therefore, effects of beam steering due to refractive index variations in the optical path were small. Laser line filters (10 nm bandwidth), a chopper operating at $1500 \mathrm{~Hz}$, a carrier amplifier system, and a $600-\mathrm{Hz}$ fourth-order low-pass filter were used to reduce effects of background radiation and to improve signal-to-noise ratios.

Soot volume fractions were found assuming the Rayleigh limit for small particles since past multiline laser-extinction measurements for acetylene and ethylene flames suggested $\pi d_{p} / \lambda<0.5$ at a wavelength of $632.8 \mathrm{~nm}[6,7]$. For such condi- 


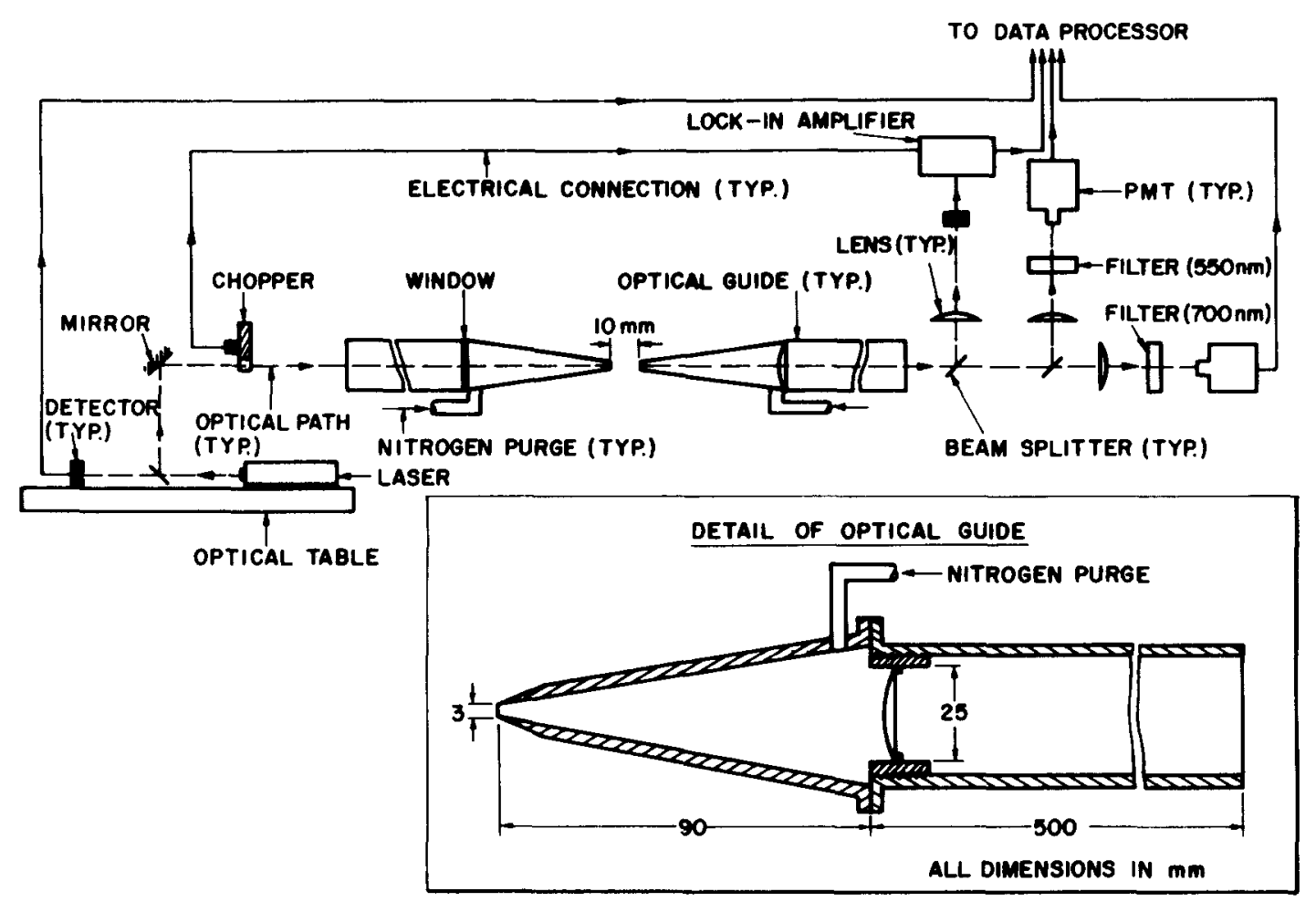

Fig. 3. Sketch of the optical probe.

tions, the differences between Rayleigh and Mie scattering predictions of soot volume fractions are less than $15 \%$ [13]. The relationship between the extinction ratio of the laser beam and the soot volume fraction for the Rayleigh limit is as follows [3]:

$f_{v}=-\ln \left(I_{\lambda} / I_{\lambda_{0}}\right) /\left(f_{\lambda} L\right)$.

The parameter $f_{\lambda}$ in Eq. 1 is a function of wavelength and the real and imaginary parts of the refractive indices of soot, $n-i \kappa$, as follows:

$f_{\lambda}=(36 \pi n \kappa / \lambda) /\left[\left(n^{2}-\kappa^{2}+2\right)^{2}+(2 n \kappa)^{2}\right]$.

The selection of soot refractive indices introduces uncertainties in the computation of soot volume fractions for fuel-rich conditions within diffusion flames. Tien and Lee [3] and Dalzell and Sarofim [14] find that soot refractive indices for hydrocarbon diffusion flames are relatively independent of fuel type (for $\mathrm{H} / \mathrm{C}$ ratios spanning the present fuels) and temperature. In contrast, a recent measurement for a kerosene diffusion flame by Batten [15] is not in good agreement with the results of Refs. 3 and 14, with effects of fuel H/C ratio cited as the potential source of the discrepancy. Furthermore, several recent measurements of soot refractive indices in premixed hydrocarbon flames have uncovered effects of fuel type, fuel-equivalence ratio, and residence time in the postflame region [16-18]. The latter observations are problematical since conditions within the soot spike at fuel-rich conditions for diffusion flames are similar to conditions in the postflame region of fuel-rich premixed flames, while residence times at these conditions are relatively long for the present experiments. Nevertheless, the majority of the results for the postflame region of premixed flames are comparable to the findings of Dalzell and Sarofim [14], 1.55-0.56i at 632.8 $\mathrm{nm}$; therefore, these values were used in order to be consistent with earlier work [4-7].

\section{Two-Wavelength Pyrometry}

Two-wavelength pyrometry was used to find temperatures along the optical path. This involved 
measurements of emission at $700 \mathrm{~nm}$ (always) and either 550 or $800 \mathrm{~nm}$, using methods described by Cashdollar [19] and Klingenberg [20] . These wavelengths only involve continuum radiation from soot and yield soot temperatures; however, gas temperatures are essentially the same since soot particles are small. The optical path was observed from one of the viewing ports while the other viewing port served as a cold boundary to limit the length of the optical path. The emission signal was focused through two beamsplitters to impinge on two detectors (Hamamatsu photomultiplier tubes, model R316) while passing through appropriate line filters $(10 \mathrm{~nm}$ halfwidth). The output signals were split, with one portion being amplified 100:1 while the other portion went directly to the analog-to-digital converter, in order to increase the dynamic range of the instrument.

Assuming homogeneous conditions along the optical path, and negligible radiation from the cold background, Planck's Law gives the following expression for the voltage output of the detector at wavelength $\lambda[19,20]$ :

$$
V_{\lambda}=A b_{\lambda} \varepsilon_{\lambda}\left(2 \pi h c^{2} / \lambda^{5}\right) /[\exp (h c / \lambda k T)-1] \text {, }
$$

where $A$ and $b_{\lambda}$ are the wavelength independent and wavelength dependent proportionality factors of the instrument. For present conditions, the exponential term in Eq. 3 is $\rightarrow 1$; therefore, $T$ can be found from measurements of $V_{\lambda}$ at two wavelengths, as follows:

$$
\begin{aligned}
T= & \frac{h c}{k}\left(\frac{1}{\lambda_{1}}-\frac{1}{\lambda_{2}}\right) \\
& \ln \left[\left(\frac{\varepsilon_{\lambda 1}}{\varepsilon_{\lambda 2}}\right)\left(\frac{b_{\lambda 1}}{b_{\lambda 2}}\right)\left(\frac{V_{\lambda 1}}{V_{\lambda 2}}\right)\left(\frac{\lambda_{2}}{\lambda_{1}}\right)^{5}\right] .
\end{aligned}
$$

The ratio of the $\varepsilon_{\lambda i}$ was obtained from the laser extinction measurements of $f_{v}$, as follows:

$\varepsilon_{\lambda i}=1-\exp \left(-f_{v} L f_{\lambda i}\right)$.

There is little change in the refractive indices of soot over the wavelength range $550-800 \mathrm{~K}[3$, 14]; therefore, $f_{\lambda i}$ in Eq. 5 was computed from
Eq. 2 using the same values as the soot volume fraction measurements.

\section{Data Acquisition}

The combined laser-extinction and two-wavelength pyrometry measurements yielded six output signals that were sampled at $700 \mathrm{~Hz}$. The procedure involved collecting 500 samples in clear air, as a reference, and 3500 samples within the flame. Results involving temperatures less than $900 \mathrm{~K}$ and soot volume fractions less than 0.01 $\mathrm{ppm}$ were discarded since sensitivity was not adequate in these ranges.

Aside from gradient broadening, which has already been discussed, experimental uncertainties of the soot volume fraction measurements were largely due to uncertainties in the estimates of the refractive indices of soot, the Rayleigh scattering approximation, signal-to-noise ratios, and discretization errors of the digital data acquisition system. Uncertainties due to refractive indices are relatively large in the absolute sense, with values within the range reported by Tien and Lee [3], Dalzell and Sarofim [14], and Charalampopoulos and coworkers $[16,17]$, yielding variations of soot volume fractions up to $25 \%$. For this range of refractive indices, experimental uncertainties of soot volume fractions are less than $40 \%$ for $f_{v}>0.1 \mathrm{ppm}$, increasing to roughly $60 \%$ for $f_{v} \approx 0.01 \mathrm{pm}$. Present results were repeatable well within these limits because a single set of refractive indices were used and effects of Mie scattering were ignored. Use of the refractive indices of Habib and Vervisch [18] and Batten [15] would result in increases of soot volume fractions from the values reported here by factors of roughly 2 and 4 , respectively.

Aside from effects of gradient broadening, which were discussed earlier, experimental uncertainties of the two-wavelength pyrometer measurements were dominated by signal-to-noise ratios and the discretization errors of the digital data acquisition system. In particular, drift of the photomultiplier tubes was small (less than $1 \%$ ) while effects of refractive index uncertainties were small because a ratio of the $\varepsilon_{\lambda i}$ was used-assuming that the refractive indices were constant over the relevant wavelength range. The resulting un- 
TABLE 1

Test Conditions ${ }^{a}$

\begin{tabular}{|c|c|c|c|c|c|c|c|c|}
\hline \multirow{2}{*}{$\begin{array}{l}\text { Fuel } \\
\text { Reynolds Number }{ }^{b}\end{array}$} & \multicolumn{2}{|c|}{ Acetylene } & \multicolumn{2}{|c|}{ Propylene } & \multicolumn{2}{|c|}{ Ethylene } & \multicolumn{2}{|c|}{ Propane } \\
\hline & 470 & 840 & 750 & 1370 & 480 & 900 & 770 & 1940 \\
\hline Richardson number ${ }^{c}$ & 68 & 22 & 108 & 32 & 77 & 22 & 116 & 18 \\
\hline Heat release rate $(\mathrm{kW})$ & 10.1 & 18.0 & 11.5 & 21.1 & 7.8 & 14.4 & 13.0 & 32.7 \\
\hline Radiative heat loss fraction $(\%)$ & 62 & 61 & 40 & 44 & 36 & 40 & 25 & 28 \\
\hline Flame height $(\mathrm{mm})^{d}$ & 400 & 550 & 540 & 720 & 460 & 670 & 550 & 890 \\
\hline Residence time $(\mathrm{ms})^{e}$ & 257 & 295 & 504 & 600 & 334 & 360 & 552 & 660 \\
\hline
\end{tabular}

$a$ Vertical fuel injection into still air at NTP from a 50-mm-diameter burner. Acetylene: Commercial Grade, Detroit Welding Co.; propylene and ethylene: chemically Pure Grade, Linde Division of Union Carbide and Air Products and Chemicals Co.; propane: chemically Pure Grade, Matheson Gas Products.

${ }^{b} \operatorname{Re}=u_{0} d / \nu_{0}$, based on average velocity at burner exit and burner gas properties.

${ }^{c} \mathrm{Ri}=a d / u_{0}^{2}$ based on average velocity at burner exit.

${ }^{d}$ Visible flame height from photographs.

e Time between termination of fuel flow and disappearance of all flame luminousity.

certainties of the temperature measurements are estimated to be less than $40 \mathrm{~K}$ for $f_{v}>0.1 \mathrm{ppm}$, increasing to $80 \mathrm{~K}$ for $f_{v} \approx 0.01 \mathrm{ppm}$. Crosschecks of the results using the two wavelength pairs $(550,700 \mathrm{~nm}$ and $700,800 \mathrm{~nm})$, as well as repeatability checks, were well within these estimates.

\section{Test Conditions}

The test conditions are summarized in Table 1. Two flame operating conditions, with roughly a 2:1 change in fuel flow rate, were used for each fuel. Burner Reynolds numbers were in the range 470-1940, but the flames were strongly buoyant and the burner Reynolds number is not a good indicator of their properties: the region where measurements were made was turbulent. The flames corresponded to pool-like fires with burner exit Richardson members greater than 18 and ratios of the flame height to the burner exit diameter less than 18. Radiative heat loss fractions for each fuel were nearly constant, typical of strongly buoyant flames [1].

Flame heights and residence times were measured in the same manner as in Ref. 5. Flame heights were taken as averages from motion pictures of the flames in a darkened room. Residence times were measured from dark-field motion picture photographs as well: they were taken to be the time interval between ending the fuel flow rate with a shutter at the burner exit and the disappearance of all flame luminousity on the films.

Flame heights were in the range $400-900 \mathrm{~mm}$, which provided reasonable spatial resolution for the optical probe. Flame residence times were all greater than $250 \mathrm{~ms}$. Except for propane, this was sufficient for the flames to be in the long-residence-time regime where soot generation efficiencies are independent of flame operating conditions. As noted in Ref. 5, the long-residencetime regime is only approached for present operating conditions for propane because reaching this condition would require excessively large flames for laboratory conditions. Flame residence times vary rather slowly with fuel flow rate [5]; therefore, flame residence-time variations were not large for each fuel, ca. $20 \%$. Instead, effective residence times were varied by considering different heights above the burner over a relatively wide range, e.g., $x / d=2.5,3.8$, and 5.7.

\section{RESULTS AND DISCUSSION}

\section{Flame Position and Operating Conditions}

In order to obtain data over the full range of conditions where soot was present in the fuel-rich (underfire) region, measurements were made at various radial positions for each height above the 


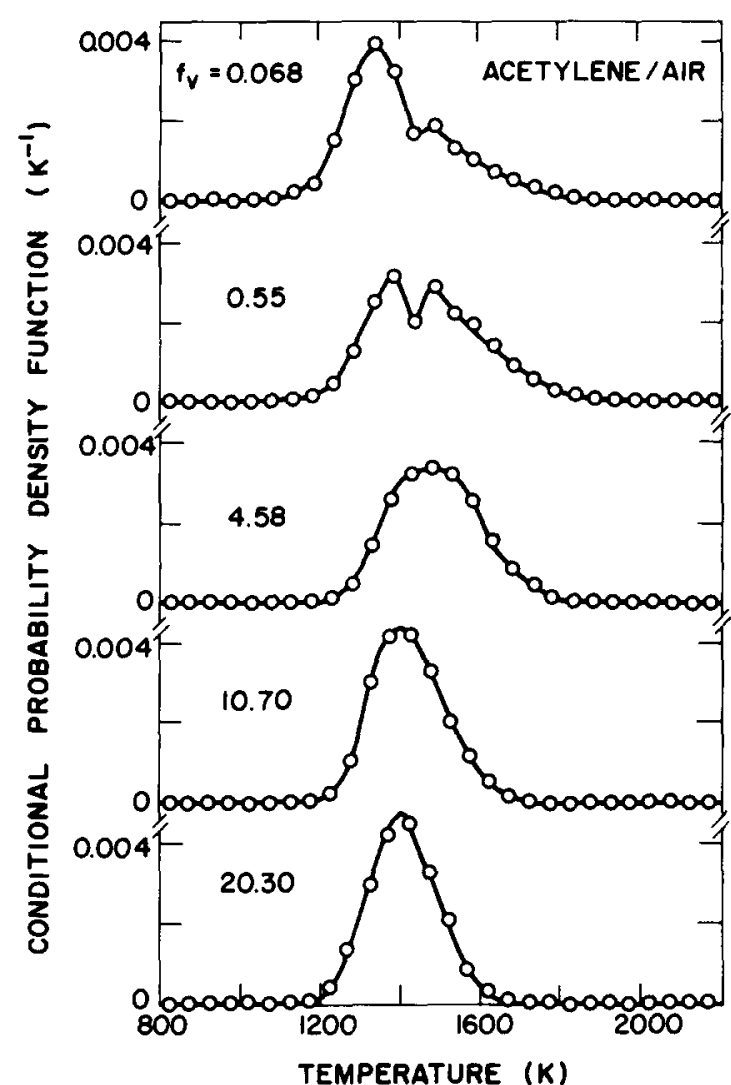

Fig. 4. Conditional pdfs of temperature for turbulent acetylene/air diffusion flames.

burner, as follows: $r / x=0-0.12,0-0.15$, and $0-0.18$ for $x / d=2.5,3.8$, and 5.7 , respectively. However, an effect of position or fuel flow rate was not observed: such changes only served to emphasize results at different levels of mixing (or mixture fractions) of the flow. Thus, in order to avoid cluttering the plots of the results, the radial position is never indicated while the axial position and burner Reynolds number are only indicated on the plots of temperature-soot volume fraction correlations. Naturally, the absence of effects of position and flow rate on relationships between temperatures and soot volume fractions for a particular fuel is supportive of the existence of state relationships for these quantities in the underfire region.

\section{Conditional pdfs of Temperature}

Probability density functions (pdfs) of temperature, conditioned on soot volume fraction, pro-

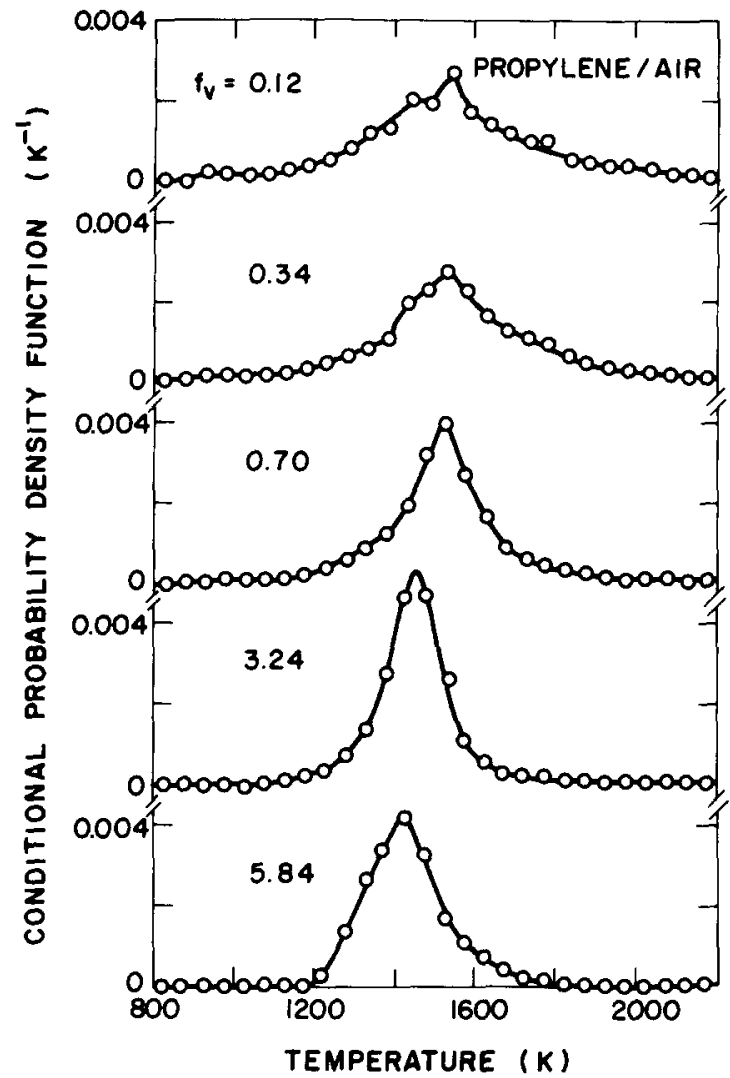

Fig. 5. Conditional pdfs of temperature for turbulent propylene/air diffusion flames.

vide a useful indication of the character of the measurements. These results were obtained by ordering all the data for a particular fuel by soot volume fraction and then separating the data into five groups each containing roughly $64,000 \mathrm{mem}$ bers. The mean soot volume fraction and the pdf of temperature were then determined for each group.

The resulting conditional pdfs for turbulent acetylene, propylene, ethylene, and propane flames are illustrated in Figs. 4-7. This ordering corresponds to decreasing propensity to soot, based on laminar flame heights at the normal smoke point $[5,21]$. The present results indicate that the same ordering is maintained in the underfire region with respect to the maximum groupaveraged soot volume fraction for each fuel. The conditional pdfs of temperature exhibit a single, relatively sharp, peak at the highest soot volume fraction for each fuel. As soot volume fractions 


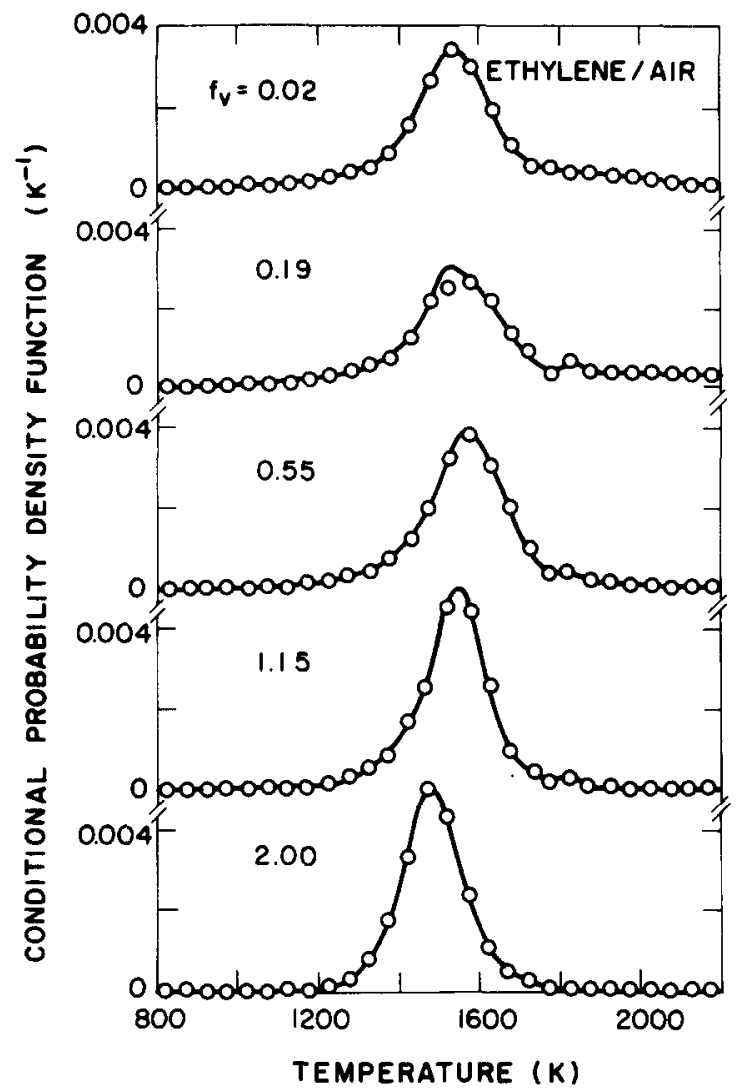

Fig. 6. Conditional pdfs of temperature for turbulent ethylene/air diffusion flames.

decrease, however, the conditional pdfs of temperature become progressively broader. At the lowest soot volume fractions considered, the conditional pdfs of temperature tend to split into two peaks, although the high-temperature peak is never very prominent and it is not observed at all for propylene. Even with the broadening, however, the temperature ranges of the conditional pdfs of temperature are relatively narrow in spite of variations of soot volume fractions in the range $10^{2}-10^{4}$ for the various fuels.

Many of the features of Figs. 4-7 can be reconciled with state relationships within the soot spikes for fuel-rich conditions-typified by the results illustrated for acetylene and ethylene in Fig. 1. First of all, the maximum group-averaged soot volume fractions for acetylene and ethylene are ca. 20 and 2 ppm for both the present results and the laminar flame results illustrated in Fig. 1.

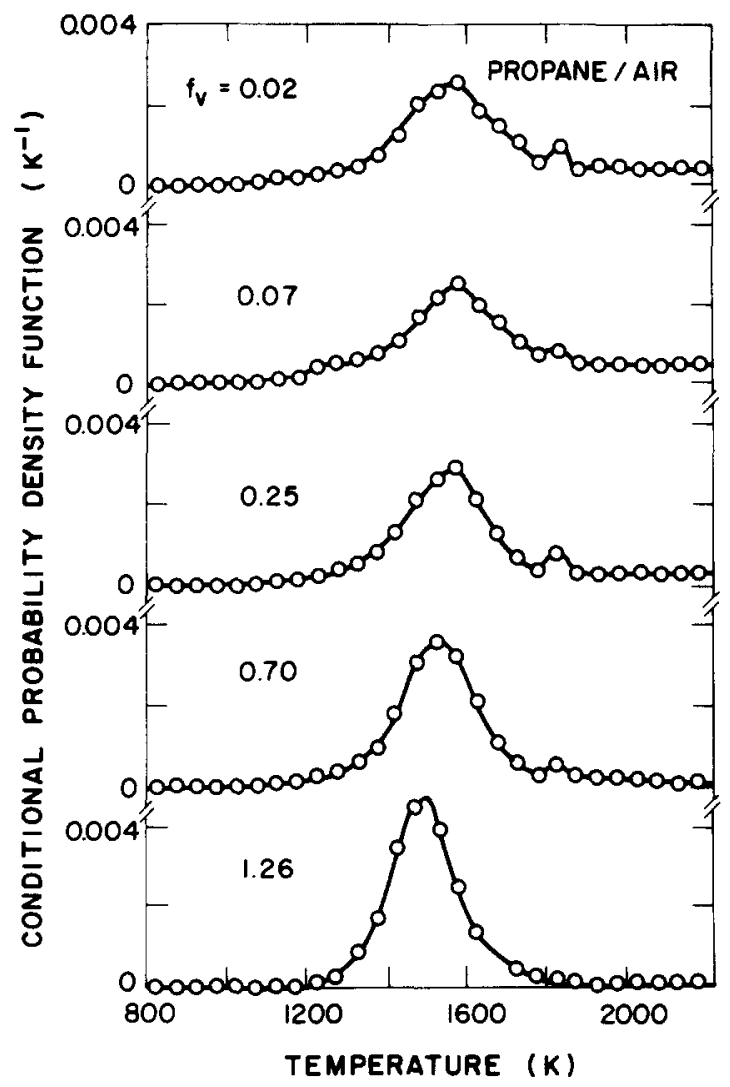

Fig. 7. Conditional pdfs of temperature for turbulent propane/air diffusion flames.

Secondly, maximum soot volume fractions in the soot spike of the state relationships of Fig. 1 are associated with a relatively narrow range of temperatures; similar behavior in the turbulent flames should yield a single, relatively sharp peak in the conditional pdf of temperature at maximum soot volume fractions, which agrees with the results of Figs. 4-7. Finally, lower values of soot volume fractions involve the two sides of the state relationships, where temperatures are somewhat different; this should yield broader peaks in the conditional pdfs of temperature, and possibly splitting into two peaks at the lowest soot volume fractions, which is also in accord with the results seen in Figs. 4-7.

Several properties of the conditional pdfs of temperature are summarized as a function of mixture fraction in Table 2, as follows: mean temperatures, temperatures of the low- and high-temper- 
TABLE 2

Properties of Conditional pdfs of Temperature

\begin{tabular}{|c|c|c|c|c|}
\hline$f_{v}$ & $\mathbf{T}_{\mathbf{M}}(\mathbf{K})$ & $T_{L}(\mathrm{~K})$ & $T_{U}(\mathrm{~K})$ & $\sigma(\mathbf{K})$ \\
\hline \multicolumn{5}{|c|}{ Acetylene } \\
\hline 0.068 & 1395 & 1320 & 1470 & 140 \\
\hline 0.55 & 1465 & 1380 & 1470 & 135 \\
\hline 4.58 & 1485 & 1420 & 1520 & 110 \\
\hline 10.7 & 1425 & 1410 & - & 95 \\
\hline 20.3 & 1415 & 1400 & - & 90 \\
\hline \multicolumn{5}{|c|}{ Propylene } \\
\hline 0.12 & 1520 & 1540 & - & 210 \\
\hline 0.34 & 1535 & 1520 & - & 200 \\
\hline 0.70 & 1505 & 1520 & - & 150 \\
\hline 3.24 & 1455 & 1450 & - & 120 \\
\hline 5.84 & 1445 & 1420 & - & 120 \\
\hline \multicolumn{5}{|l|}{ Ethylene } \\
\hline 0.02 & 1550 & 1520 & - & 175 \\
\hline 0.19 & 1575 & 1520 & 1810 & 195 \\
\hline 0.55 & 1570 & 1560 & 1810 & 150 \\
\hline 1.15 & 1530 & 1540 & 1820 & 110 \\
\hline 2.00 & 1490 & 1460 & - & 95 \\
\hline \multicolumn{5}{|l|}{ Propane } \\
\hline 0.02 & 1580 & 1560 & 1840 & 195 \\
\hline 0.07 & 1590 & 1560 & 1820 & 200 \\
\hline 0.25 & 1570 & 1560 & 1810 & 190 \\
\hline 0.70 & 1530 & 1520 & 1810 & 150 \\
\hline 1.26 & 1490 & 1490 & - & 110 \\
\hline
\end{tabular}

ature peaks (when present), and the standard deviations of the distributions. In general, mean temperatures of the distributions for each fuel vary less than $100 \mathrm{~K}$ over the whole range of soot volume fractions. Mean temperatures reach a maximum at intermediate values of soot volume fractions. This reflects the fact that the maximum soot volume fraction and temperature conditions do not coincide, on the one hand, whereas low soot volume fractions are associated with low temperatures at the start of formation of soot on the other. Maximum mean temperatures of the distributions increase in the order acetylene, propylene, ethylene, and propane. This follows the order of reduction of the radiative heat loss fraction of the fuels (Table 1), which is expected to increase flow temperatures.

Mean temperatures in Table 2 are generally just slightly above the temperature of the low- temperature peak because the high-temperature peak is not very prominent. Differences in temperature between the low- and high-temperature peaks also increase in the order of reduced radiative heat loss fractions. This suggests that the high-temperature peak is associated with the fuel-lean side of the soot spike, and exhibits higher temperatures as radiative heat losses are reduced, while temperatures where soot first begins to appear are likely to be similar for all the fuels.

The standard deviations of the conditional pdfs of temperature in Table 2 are approximately 100 $\mathrm{K}$ at the maximum soot volume fraction. This is roughly twice the uncertainty estimate of the temperature measurements at this condition, ca. 40 $K$, even though peak soot volume fractions should be associated with a single temperature if the soot volume fraction state relationship concept is exact. Nevertheless, this behavior is not surprising in view of potential effects of gradient broadening of measurements along a finite-length optical path and the grouping of data to find a conditional pdf of temperature. On the other hand, some variation of temperatures at peak soot volume fractions, similar to the results in the laminar soot spike of acetylene in Fig. 1, cannot be ruled out. The progressive increase of the standard deviations of the conditional pdfs of temperature with decreasing soot volume fractions is consistent with the wider range of temperatures anticipated near the base of the soot spike, as noted earlier.

\section{Temperature-Soot Volume Fraction Correlations}

The correlations between instantaneous temperatures and soot volume fractions for turbulent acetylene, propylene, ethylene, and propane flames are illustrated in Figs. 8-11. Results in the upper part of the figures are for the underfire region. In order to avoid excessive overlapping of symbols on the plots, each of the data points for the underfire region represents the average of the nearest 100 instantaneous determinations of soot volume fractions and temperatures. The data in the underfire region represent a range of radial positions and are identified to indicate heights 


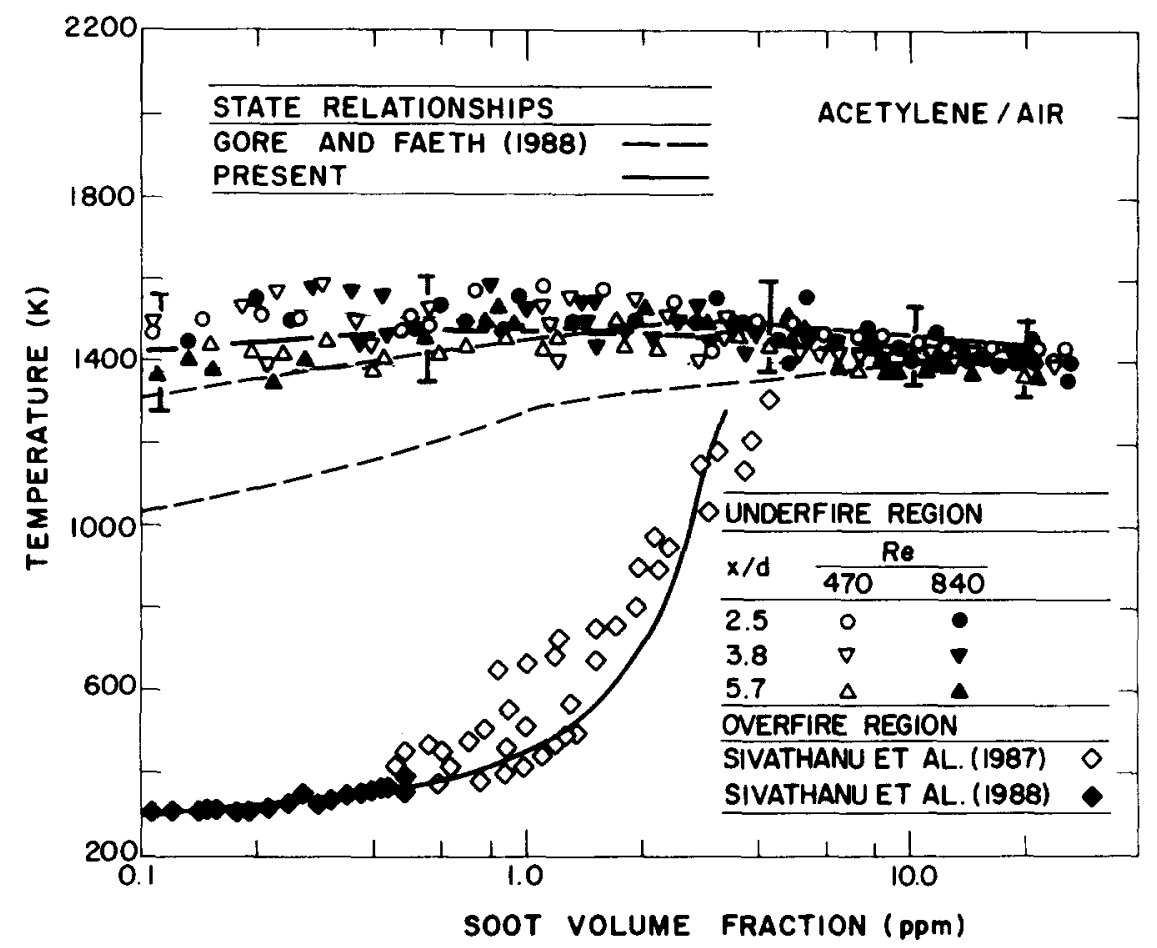

Fig. 8. Correlations between soot volume fraction and temperature for turbulent acetylene/air diffusion flames.

above the burner and burner Reynolds numbers; however, changes of these variables did not affect the results, as noted earlier.

State relationships illustrated in Figs. 8-11 for the underfire region include results based on the measurements within laminar flames reported by Gore and Faeth [6, 7] for acetylene and ethylene, and correlations obtained from the present flames. The correlations reported in Refs. 6 and 7 were obtained by transcribing the state relationships in the soot spikes of Fig. 1 to the soot volume fraction-temperature coordinates of Figs. 8-11. The temperatures needed for this change of variables were computed in the same manner as in Refs. 6 and 7. This involved computations of flame temperature as a function of mixture fraction using the measured concentrations of major species from the state-relationship correlations and thermochemical properties from the Gordon and McBride [22] code. It was assumed for these computations that the flames lost a fixed fraction of their chemical energy release at each mixture fraction due to radiation, with this fraction being the same as the radiative heat loss fraction of the flame as a whole. Radiative heat loss fractions were measured for the various fuels; as noted earlier, they only depend on fuel type for strongly buoyant flames [1].

The present correlations for the underfire region appearing in Figs. 8-11 were taken to be the locus of the mean temperatures of the conditional pdfs of temperature, summarized in Table 2. The standard deviations of the conditional pdfs are also marked on the plots in order to provide a quantitative measure of the span of the temperature data. The lower peaks of the conditional pdfs are relatively close to the mean temperatures; the upper peaks are roughly near the upper end of the standard deviation limits at low soot volume fractions.

Results plotted in the lower part of Figs. 8-11 involve the measurements and state relationship correlations for the fuel-lean (overfire) region of turbulent flames from Refs. 4 and 5. These measurements and correlations were both transcribed from soot volume fraction-mixture fraction coor- 


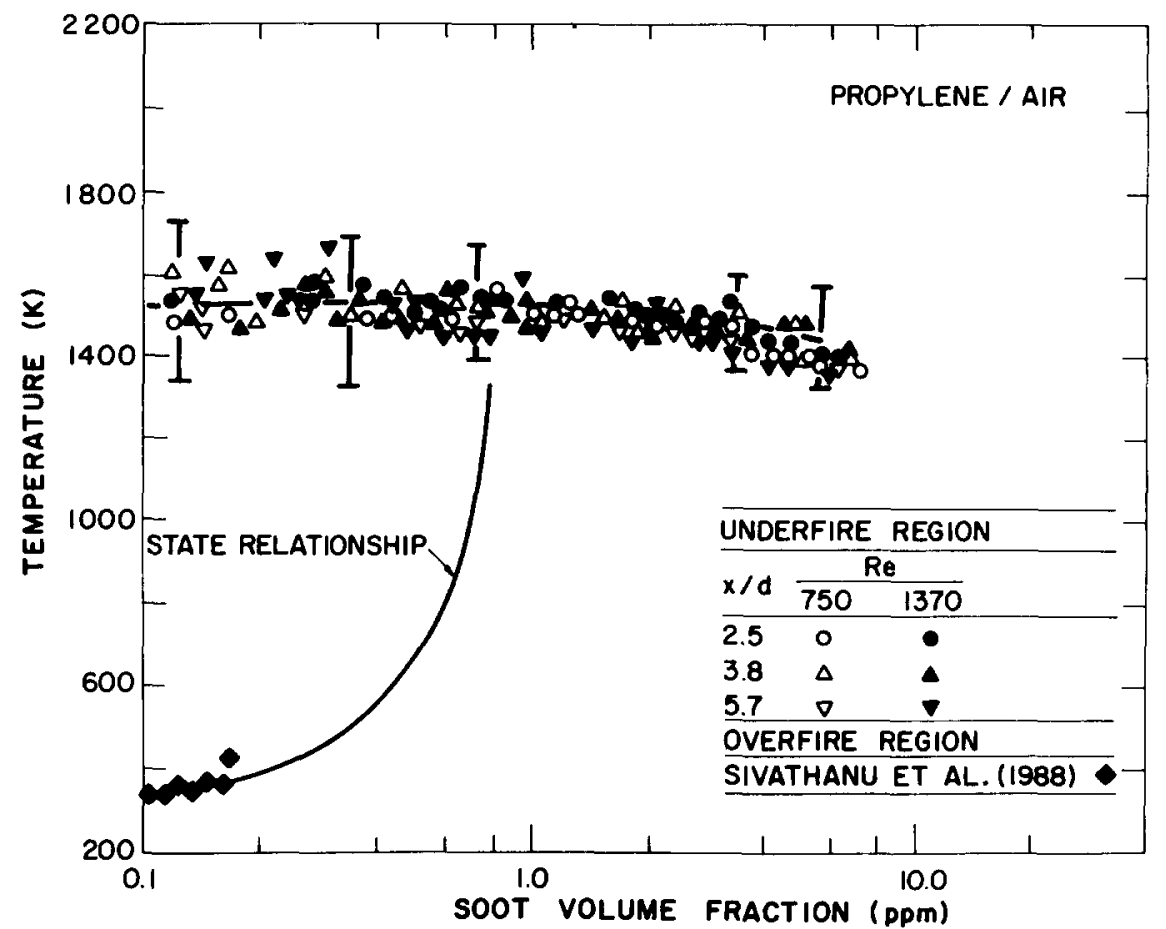

Fig. 9. Correlations between soot volume fraction and temperature for turbulent propylene/air diffusion flames.

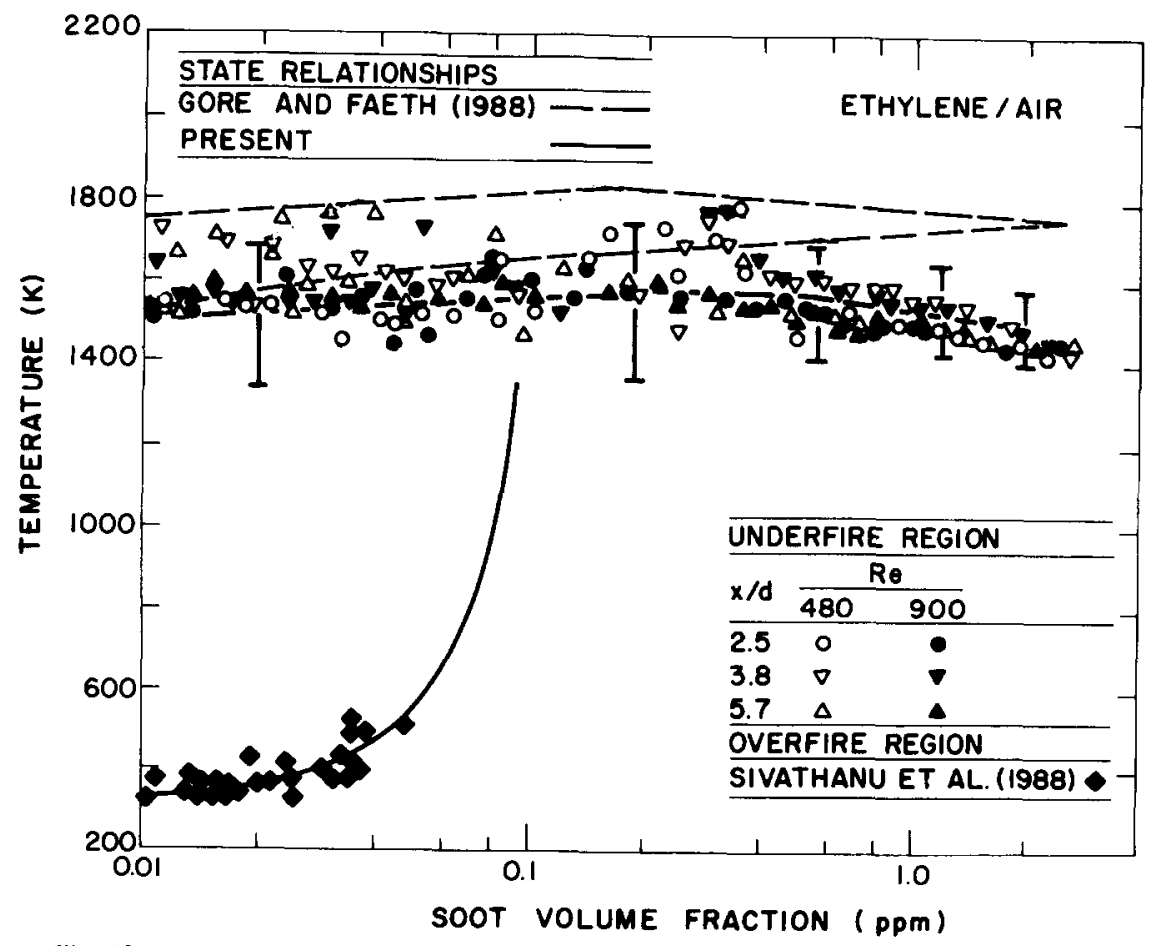

Fig. 10. Correlations between soot volume fraction and temperature for turbulent ethylene/air diffusion flames. 


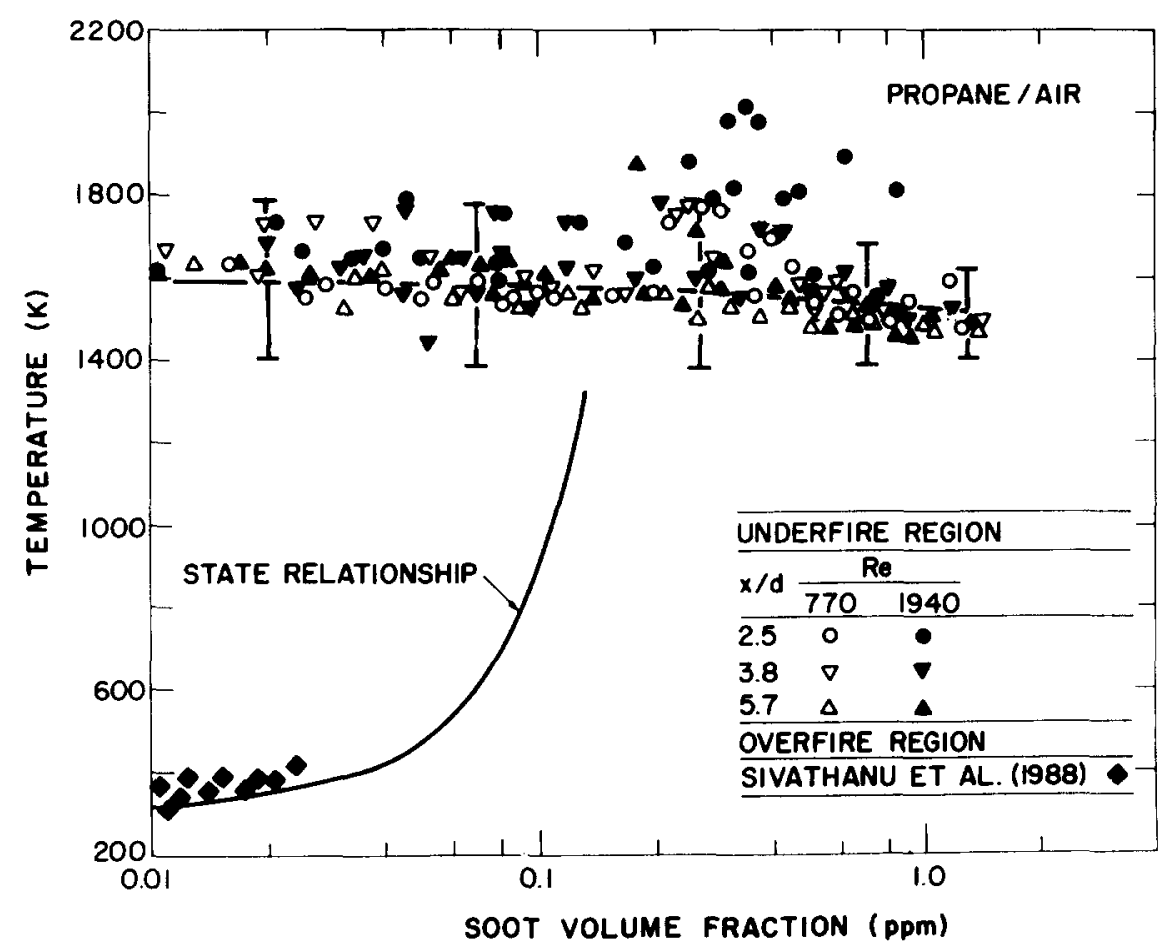

Fig. 11. Correlations between soot volume fraction and temperature for turbulent propane/air diffusion flames.

dinates to the coordinates of Figs. 8-11 in the same manner as the underfire soot volume fraction state relationship correlations. The overfire data and correlations pertain to the long residence-time regime; therefore, even though a range of positions and flame operating conditions were involved, these variables are not indicated since their effect is small.

The results illustrated in Figs. 8-11 strongly suggest the presence of soot spikes in the underfire region of the turbulent flames, analogous to the soot spikes observed in the fuel-rich region of laminar flames. This can be seen by comparing the soot spike state relationships of Refs. 6 and 7 for acetylene and ethylene, which were obtained in laminar flames, with the present measurements in turbulent flames (Figs. 8 and 10). First of all, maximum soot volume fractions for the laminar and turbulent flames are essentially the same, as noted earlier. Similarly, the temperature ranges of the present measurements are nearly the same as the span of the laminar state relationships at low soot volume fractions. The temperature lev- els of the soot spike for various soot volume fractions differ somewhat for the laminar and turbulent flames, but these differences can easily result from attempts to fit a state relationship to the limited and scattered measurements for laminar flames (see Fig. 1) as well as uncertainties in the estimates of state relationships for temperatures. The narrow temperature range where soot is present in the underfire region for propylene and propane (Figs. 9 and 11) also suggests a soot spike for these fuels because the mixture fraction range must be limited as well.

The narrow temperature ranges where soot is observed in the underfire region in Figs. 8-11 also tends to support past simplifications of constant-temperature soot layers for estimates of continuum radiation from flames [1]. This approximation tends to be more appropriate for heavily sooting fuels like acetylene and propylene where large radiative heat losses reduce peak temperatures in the flames. In contrast, propane only has a radiative heat loss fraction of $25 \%-28 \%$ (Table 1) and exhibits a span of temperatures in excess 
of $400 \mathrm{~K}$ for relatively-high soot volume fractions; therefore, the constant-temperature soot layer approximation is clearly less satisfactory for this fuel. Large flames of even heavily sooting fuels may also be problematical because they are more adiabatic as a whole since soot in the overfire region shields heat losses from the high-temperature regions of the flow [6, 7]. However, portions of the soot layers within these flames still must be relatively cool, promoting local radiative exchange from high- to low-temperature regions of the soot layer; thus, local behavior within very large flames may not be very different from present observations. However, additional study is needed to determine whether this conjecture is true.

Extrapolation of the overfire correlation meets the soot spike abruptly in Figs. 8-11, analogous to the behavior of the soot volume fraction state relationships illustrated in Fig. 1. This occurs since there are two paths to small soot volume fractions on the lean side of the maximum soot volume fraction. One path represents approach to stoichiometric conditions along the sides of the laminar flamelets, similar to processes along the sides of laminar flames. In this case soot volume fractions become small as soot oxidation is enhanced near the stoichiometric condition while temperatures remain relatively high. These conditions are most representative of the high-temperature side of the soot spike seen in Figs. 8-11-perhaps corresponding to the high-temperature peak of the conditional pdf of temperature. The other path involves passage of the soot layer as a whole through the tip of a turbulent flamelet, analogous to processes near the tip of a sooting laminar flame. In this case, once soot oxidation ceases, additional reductions of concentrations of soot are only due to passive mixing in the overfire region, and follow the overfire correlations illustrated in Figs. 8-11. As a result, the intersection of the two correlations represent conditions when soot oxidation is quenched. Thus, the overfire and underfire correlations are relevant to two different statistical populations and are separated by a narrow oxidation zone as the soot layer passes through mixture fractions near stoichiometric conditions.

\section{CONCLUSIONS}

Instantaneous soot volume fractions and temperatures were measured in the fuel-rich (underfire) region of turbulent acetylene, propylene, ethylene, and propane diffusion flames burning in still air. The test flames were relatively large with characteristic residence times greater than 250 $\mathrm{ms}$, placing them in the regime where soot generation efficiencies are independent of position in the overfire region and burner operating conditions [5]. The test flames were also highly buoyant pool-like fires with burner exit Richardson numbers greater than 18 so that the results are largely relevant to natural fires. The main conclusions of the study for these test conditions are as follows:

1. Instantaneous temperatures and soot volume fractions are highly correlated in the fuel-rich (underfire) region. These correlations depend on fuel type but were essentially independent of burner operating condition and position in the underfire region.

2. The correlations between temperatures and soot volume fractions in the underfire region are consistent with the properties of soot volume fraction state relationships for the soot spike region of laminar flames. In particular, maximum soot volume fractions and temperature ranges within the laminar and turbulent soot spikes were essentially the same for acetylene and ethylene flames-the only flames where this comparison could be made. This suggests that useful information concerning soot volume fraction state relationships can be obtained in laminar flames where measurements are much easier than in turbulent flames.

3. The soot spike in the underfire region of turbulent flames exhibits a relatively narrow range of temperatures - particularly for heavily sooting fuels where radiative heat loss fractions from the flame are relatively high. This provides some justification for the use of a constant-temperature soot layer approximation for estimates of continuum radiation from flames.

Although present findings support the existence 
of soot volume fraction state relationships in turbulent flames, for the purposes of radiation predictions, the results are only provisional. Measurements of soot volume and mixture fractions in turbulent flames are still needed to directly evaluate the soot volume fraction state relationship concept. Furthermore, additional measurements in laminar flames, along the lines of Refs. 6 and 7, are also needed to better establish the correlation between soot volume fraction state relationships in laminar and turbulent flames. Finally, conclusions about soot volume fraction state relationships are influenced by the properties of the refractive indices of soot for long residence times in fuel-rich soot layers; therefore, existing controversies concerning the refractive indices of soot in flames [3, 14-18] must be resolved in order to make substantive progress on this issue.

This research was supported by the Center for Fire Research of the National Institute of Standards and Technology (formerly the $\mathrm{Na}$ tional Bureau of Standards), Grant No. 60NANB5D0576 and 60NANB8D0833 with D. $D$. Evans and $H$. R. Baum serving as Scientific Officers.

\section{REFERENCES}

1. deRis, J., Seventeenth Symposium (International) on Combustion, The Combustion Institute, Pittsburgh, 1978 , p. 1003.

2. Faeth, G. M., Gore, J. P., Chuech, S. G., and Jeng, S.-M., Annu. Rev. Num. Fluid Mech. and Heat Trans. 2:1 (1989).

3. Tien, C. L., and Lee, S. C., Prog. Ener. Combust. Sci. 8:41-59 (1982).
4. Sivathanu, Y. R., Gore, J. P., and Faeth, G. M., Combust. Flame 73:315-329 (1988).

5. Sivathanu, Y. R., and Faeth, G. M., Combust. Flame 81:133-149.

6. Gore, J. P., Faeth, G. M., Twenty-First Symposium (International) on Combustion, The Combustion Institute, Pittsburgh, 1986, p. 1521.

7. Gore, J. P., and Faeth, G. M., J. Heat Trans. 110:173-181 (1988).

8. Bilger, R. W., Combust. Flame 30:277-284 (1977).

9. Liew, S. K., Bray, K. N. C., and Moss, J. B., Combust. Sci. Technol. 27:69-73 (1981).

10. Liew, S. K., Bray, K. N. C., and Moss, J. B., Combust. Flame 56:199-213 (1984).

11. Faeth, G. M., and Samuelsen, G. S., Prog. Ener. Combust. Sci. 12:305-372 (1986).

12. Newman, J. S., and Steciak, J., Combust. Flame 67:55-64 (1987).

13. Santoro, R. J., Dobbins, R. A., and Semerjian, H. G., Prog. Astronaut. Aeronaut. 92:343-382 (1984).

14. Dalzell, W. H., and Sarofim, A. F., J. Heat Trans. 91:100-104 (1969).

15. Batten, C. E., Appl. Opt. 24:1193-1199 (1985).

16. Charalampopoulos, T. T., and Felske, J. D., Combust. Flame 68:283-294 (1987).

17. Charalampopoulos, T. T. and Chang, H., Combust. Sci. Technol. 59:401-421 (1988).

18. Habib, Z. G., and Vervisch, P., Combust. Sci. Technol. 59:261-274 (1988).

19. Cashdollar, K. L., Appl. Opt. 18:2595-2597 (1979).

20. Klingenberg, G., Opt. Eng. 24:692-696 (1985).

21. Schug, K. P., Manheimer-Timnat, Y., Yaccarino, P., and Glassman, I., Combust. Sci. Technol. 22:235-250 (1980).

22. Gordon, S., and McBride, B. J., Computer Program for Calculation of Complex Chemical Equilibrium Compositions, Rocket Performance, Incident and Reflected Shocks and Chapman-Jouguet Detonations, NASA SP$273,1971$.

Received 26 May 1989; revised 13 September 1989. 